\title{
Characterizing the attitudes and motivations of Ontario dairy producers toward udder health
}

\author{
D. A. Shock, ${ }^{1} \odot$ J. B. Coe, ${ }^{2}$ S. J. LeBlanc, ${ }^{2} \odot$ K. E. Leslie, ${ }^{2} \odot$ D. Renaud, ${ }^{1,2} \oplus$ S. Roche, ${ }^{1,2} \odot$ K. Hand, ${ }^{1}{ }^{\oplus}$ \\ M. A. Godkin, ${ }^{3}$ (i) and D. F. Kelton ${ }^{2 *}$ (i) \\ ${ }^{1}$ ACER Consulting, Guelph, Ontario, N1G 5L3, Canada \\ ${ }^{2}$ Department of Population Medicine, University of Guelph, Guelph, Ontario, Canada, N1G 2W1 \\ ${ }^{3}$ Veterinary Science and Policy Group, Ontario Ministry of Agriculture and Food, Guelph, Ontario, Canada, N1G 4Y2
}

\section{ABSTRACT}

Considerable research has focused on identifying risk factors for intramammary infections, yet mastitis remains a pervasive disease on dairy farms. Increasingly, researchers are appreciating the role of dairy producer mindset in determining management style and thus udder health status of the herd. The objective of this study was to explore the attitudes and motivations of Ontario dairy farmers toward udder health in herds with varying bulk milk somatic cell count (BMSCC). In December 2011, 5 focus groups were conducted across Ontario, Canada, with independent groups of dairy producers representing low, medium, and high BMSCC herds. Groups were established based on producer's weighted BMSCC levels as recorded over the summer of 2011. A semi-structured interview guide was followed to discuss topics relating to udder health. Thematic analysis was performed on the interview transcripts. Generally, producers noted management techniques (specifically culling infected cows and monitoring BMSCC), a perceived wealth of information on mastitis control, and a proactive whole-herd management approach engender the perception of control over mastitis. Producers in the low BMSCC group were confident in their level of knowledge and control of mastitis in their herds, whereas high BMSCC producers generally felt lower levels of control. Several areas were identified by producers that counteract this perception, contributing to perceived low levels of control over mastitis. Participants identified that at certain times they do not understand the cause of BMSCC on their farm. This attitude was especially prominent in the high BMSCC group. Other times, producers cited improper sample handling, seasonal issues, perceived milk culture shortcomings, and low herd size as factors that limited their

Received March 14, 2019.

Accepted January 2, 2020.

*Corresponding author: dkelton@uoguelph.ca control over mastitis in their herds. Though producers generally have high levels of self-efficacy beliefs when it comes to udder health management, the perception still exists that, under certain situations, mastitis is uncontrollable. This highlights the fact that educational and extension efforts need to focus on ensuring that producers employ proven mastitis diagnostic, prevention, and treatment practices in a systematic manner, with realistic expectations.

Key words: udder health, mastitis, dairy cow, attitudes, motivation

\section{INTRODUCTION}

Mastitis remains one of the most common and costly diseases that the modern dairy industry continues to face (Hogeveen et al., 2011). Recent investigations have shown that it is possible to improve udder health through implementation of best management practices, tailoring recommendations to producer priorities and management style (Jansen et al., 2010a,b; Steeneveld et al., 2014). Nevertheless, a large portion of producers still do not adopt, or only partially adopt, suggested management changes (Steeneveld et al., 2014). This suggests a potential disconnect between generation, dissemination, and implementation of recommended mastitis control procedures.

Increasingly, researchers are appreciating the role that the dairy producer's mindset plays in determining management style and thus udder health status of the herd. Research shows that several factors motivate producers to lower their SCC, including the desire to have a healthier herd and to avoid financial penalty, or attain quality premiums (Jansen et al., 2009). Further, producer attitude toward mastitis prevention can explain a significant proportion of the variation in mastitis incidence in a Dutch study (Lam et al., 2011).

To understand the complex nature of producer attitudes and motivations, an approach is needed that allows for an engaged and open discussion of the issues. 
Focus groups are semi-structured group interviews, conducted by a neutral moderator and designed to explore the viewpoints, attitudes, and beliefs of targeted individuals through the ongoing and complex interaction of group participants (Krueger and Casey, 2009). This qualitative research method is designed to develop a detailed description of a person, group, or phenomenon, and in doing so, to gain a deeper understanding of their social mindset and states of being (Creswell, 2013). Given the complexity and diversity associated with producer attitudes, qualitative methods provide a means for understanding such questions (Vaarst et al., 2002; Jansen et al., 2010c).

In Ontario, Canada, bulk milk somatic cell count (BMSCC) regulation is based on weighted monthly BMSCC values. Although no financial incentive program currently exists to encourage maintenance of lower herd SCC, producers incur penalties if any 3 out of 4 consecutive monthly weighted BMSCC readings are above a set regulatory threshold. In August 2012, the regulatory threshold was decreased from 500,000 to 400,000 cells $/ \mathrm{mL}$. In addition, dairy producers in Ontario must maintain milk production levels within a narrow range of their daily quota allotment; however, producers can be allotted additional production allowance during the late summer and fall when demand for milk is greater. As such, Ontario dairy producers face different challenges in the production of milk, and as such might have differing attitudes and motivations relative to udder health. The objective of this study was, through semi-structured focus group interviews, to explore the attitudes and motivations of Ontario dairy farmers with varying BMSCC toward mastitis and udder health.

\section{MATERIALS AND METHODS}

This paper follows the consolidated criteria for reporting qualitative research (Tong et al., 2007). The 32-item checklist is presented in Appendix Table A1. The study was part of an initiative of the Dairy Farmers of Ontario (DFO, Ontario's milk marketing board) to better understand membership challenges with respect to udder health. All participating producers were provided with information sheets and asked to sign informed consent documents before focus group commencement. This research complies with all laws, regulations, and policies governing the use of human subjects in research in Canada.

\section{Producer Selection and Recruitment}

To obtain a sample of Ontario dairy producers from across the province, 2 lists of producers were generated, one containing all producers from southwestern Ontario and the other containing all producers from eastern Ontario. Lists, contact information, and BMSCC values were provided by the DFO. These 2 regions account for greater than $90 \%$ of all dairy producers (approximately 4,137 farms) across the province. The producers with a BMSCC in the highest and lowest $10 \%$ of producers in June 2011 on each list were excluded to obtain a representative sample of "average" dairy producers, as research shows that herds with moderate BMSCC levels (between 150,000 to 400,000 cells/mL) have the highest total influence on provincial BMSCC (Sargeant et al., 1998). The total sampling frame was approximately 2,978 farms $(2,084$ in southwestern Ontario, 894 in eastern Ontario). Producers were then stratified into quartiles based on their weighted monthly BMSCC levels in the summer of 2011. Producers on the lists in each BMSCC category were then randomly selected using the randomize function in Excel (Microsoft, Redmond, WA), and producers were contacted by phone to ascertain their willingness to participate. An incentive of CAD $\$ 100$ was offered to producers who attended each focus group meeting. A total of 5 groups of producers were recruited: 3 in southwestern and 2 in eastern Ontario. The 3 groups in southwestern Ontario were low (quartile 1: 0 to 25\%), medium (quartile 2: 26 to $50 \%$ ), and high (quartile 4: $75-100 \%$ ) BMSCC producers, whereas in eastern Ontario, due to logistics and a lower density of dairy producers in this region, only 2 groups were formed: low (quartile 1 and quartile 2: lowest $50 \%$ ) and high (quartile 3 and quartile 4: highest $50 \%)$ BMSCC producers. With a goal of 8 participants per focus group, random recruitment took place until a total of 40 producers had agreed to participate in the 5 scheduled focus groups.

\section{Focus Group Interviews}

The focus group interviews were conducted in Tavistock, Ontario (3), and Maxville, Ontario (2), over $3 \mathrm{~d}$ in December 2011. A semi-structured interview guide, developed based on findings of prior research into udder health in the Netherlands (Jansen et al., 2010c), was followed using a pre-tested series of standardized openended questions and follow-up probes (Appendix A). Producers were encouraged, by a trained facilitator, to discuss topics relating to: the causes and disadvantages of high SCC, perception of mastitis risk, mastitis treatment and prevention, the upcoming SCC regulatory threshold change (from 500,000 to 400,000 cells/mL in August 2012), sources of information regarding mastitis prevention, and their interaction with agricultural consultants to address udder health (Appendix A). Following the focus group discussion, participants completed 
a questionnaire that included general demographic and farm management information. A debriefing was then conducted between facilitator (MP) and assistant (DS) to ensure clarity and understanding of the discussion that had transpired. All focus groups were digitally audio-recorded and transcribed verbatim by an independent research technician that was not present for the focus groups.

\section{Data Analysis}

Following transcription, the verbatim transcripts were read by the first author (DS) while concurrently listening to the audio recordings of the focus groups to confirm the quality and accuracy of the transcriptions. Thematic analysis, a qualitative methodology employed to identify, analyze, and report patterns within written data, was used to analyze the transcripts of the focus group discussions (Braun and Clarke, 2006). The analysis started with the first author (DS) reading and re-reading all the transcripts while making notes of initial ideas and opinions emerging from the participants' discussions. A bottom-up, inductive approach to coding was taken, which meant codes were based on participant responses and interactions (Braun and Clarke, 2006). This approach ensures that the content of the focus groups drives theme development, without starting with preconceived themes for which to test. Briefly, codes were generated by identifying interesting features of the data in a systematic fashion across the entire data set. Further, related codes were grouped into descriptive themes and reviewed in relation to extracts (segments of participant's verbal responses that express a unique idea) coded across the entire data set for a theme. These initial themes were then refined and named upon discussion with JC. Ongoing analysis and reflection, based on discussions with an expert in thematic analysis (JC) and other study authors, generated a clear definition for each theme while identifying the interrelation present between all themes. The analysis process, wherein themes were developed, justified, and refined were recorded in an analysis journal to ensure reliability and trustworthiness of the analysis. All stages of analysis were completed using the program Atlas.ti (Berlin, Germany).

\section{RESULTS}

Focus group interviews ranged in length from 79 to $106 \mathrm{~min}$. The general participant and farm characteristics, including self-reported and actual BMSCC over the month of November 2011, are presented in Table 1. Approximately 200 producers were contacted to participate, of which 40 agreed $(\sim 20 \%)$. Of these
40 producers, $34(85 \%)$ attended their respective focus group. Most participants (60\%) managed tiestall herds of Holstein (90\% of the herds) cattle. All participants attending their respective focus group meeting were either the primary herd manager or were an equal managing partner with another individual.

Overall, 4 themes relating to Ontario dairy producer attitudes toward udder health were developed: "empowered management to control mastitis," "lack of power to control mastitis," "motivated management," and "frustrations." A conceptual schematic of the relationship among the themes and sub-themes has been developed (Figure 1). The focus of this paper will be on the themes surrounding perceived self-efficacy to control mastitis, namely "empowered management" and "lack of power" to control mastitis. Most discussions across all groups focused on these 2 themes. As such, the depth and breadth of information emerging from discussions made these themes the richest, most impactful ones following qualitative analysis. The remaining themes are presented in Appendix B.

\section{Theme 1: Empowered Management to Control Mastitis}

Producers participating in the focus group discussions expressed a variety of attitudes relating to their overall control of the udder health situation on their farm. For this study, the term empowerment refers to the feeling of control that participating producers had over the udder health situation of their herds. Several sub-themes emerged in relation to empowering management strategies for and controlling of mastitis, including perceived efficacy to control mastitis using management techniques, information availability, and holistic management of the herd.

Subtheme 1: Empowering Management Techniques. Participants across the 5 focus groups dedicated a notable portion of their discussion to practices that they perceive as efficacious in the control of mastitis on their farm. Control techniques such as culling high SCC cows, SCC monitoring (individual cows and BMSCC), nutrition optimization, milking equipment maintenance, milking management, and environmental cleanliness were discussed across all focus groups. One of the most commonly mentioned methods of SCC control that participants identified as being empowering was the culling of chronically high SCC cows. All groups of producers recognized the value of culling as a method that empowered control over the udder health situation on their farm; however, producers in high SCC groups expressed concerns about the potential negative effects of focusing solely on SCC when culling as well as a concern this could result in culling too many cows. As 
Shock et al.: ATTITUDES, PERCEPTIONS, AND MOTIVATIONS TOWARD UDDER HEALTH

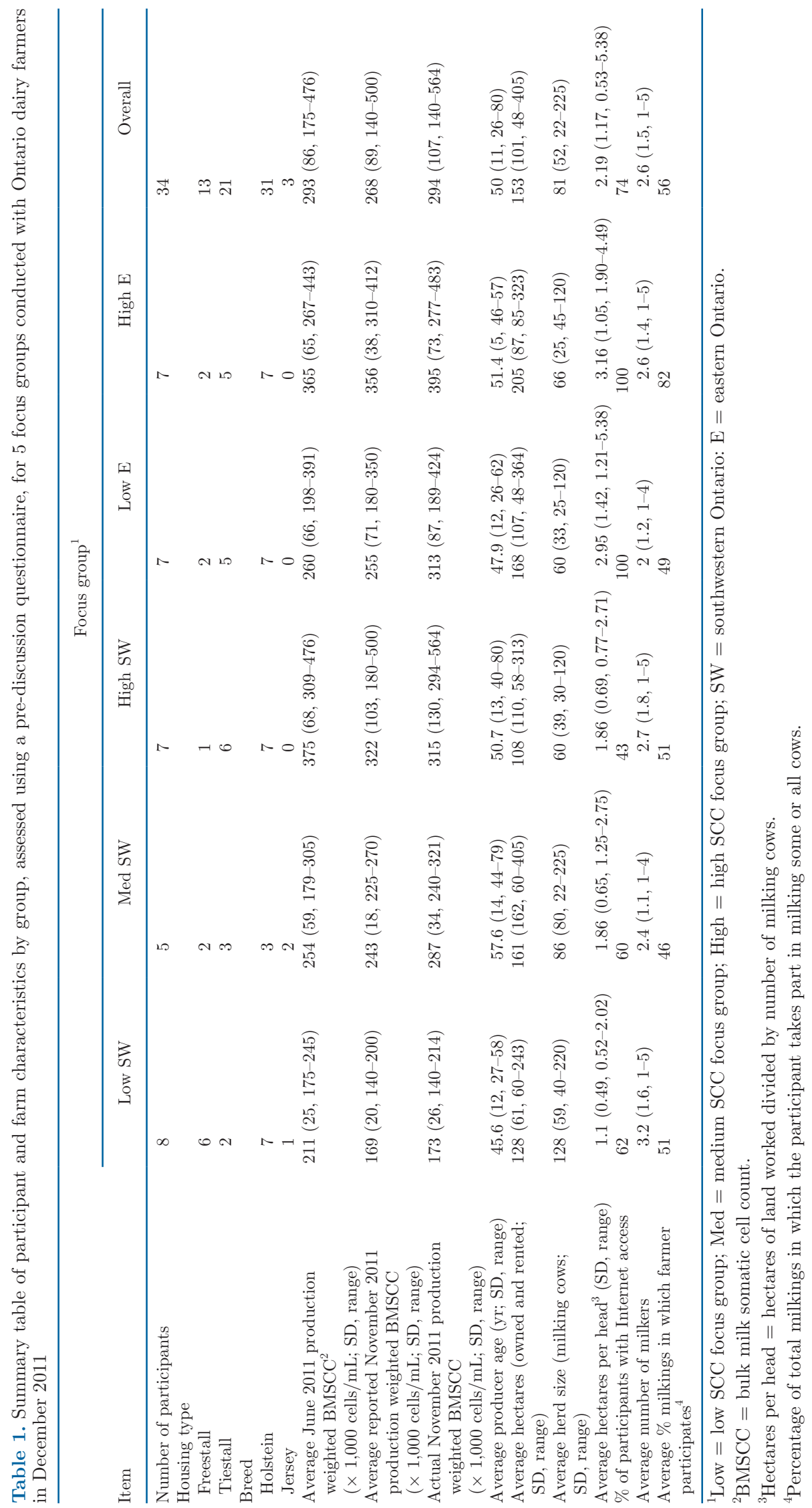


one producer in the low SCC group stated, "You have to cull. If you want to get rid of problems you have to cull cows out too, with higher cell counts. That's when you can fix your problems the quickest." In support of this notion, another producer in the same group stated, "That's what they say, if you have a cow with mastitis, that you treat them right away. If the mastitis comes back, you have to ship them then, end of story." Some producers in the high SCC groups expressed the view that a cow with a high SCC must have other negative attributes before they considered her a candidate for culling. One producer in the high SCC groups stated, "First thing I do is look for high ones, and hopefully they're the ones that happen to be on my cull list too, and get rid of them." Taken one step further, although acknowledging the empowering feelings that culling engenders with respect to mastitis control, producers expressed the sentiment that over-reliance on culling could be economically detrimental, particularly among those in the high SCC groups. Another producer in one of the high SCC groups stated, "But then on the other hand is like, what is the cost of it [culling high
SCC cows], like you can get the somatic cell down ... but then ... your cull rate of the cows might go up drastically, so your turnover in the herd would be a lot faster ... maybe we get a little bit more milk per cow, but does it offset the, the cost of getting that somatic down to, say, from three hundred thousand down to two hundred thousand?"

Producers across all 5 focus groups identified SCC monitoring as a management technique that further empowers them to control mastitis on their operations. Monitoring the individual cow SCC, along with actively following their bulk tank SCC online, were seen as a vitally important method to control SCC and mastitis. One producer stated the Internet was a real advantage because they could get BMSCC information following milk pickup every $2 \mathrm{~d}$ to closely monitor what was happening in the herd: "Now with the Internet, and that every pickup is only two days, I think that's a big improvement... at least you can keep track and see what's going on." Another producer mentioned, "Yeah, DHI tells you where your problems are ... are they in the first hundred days? They give you a lot of good
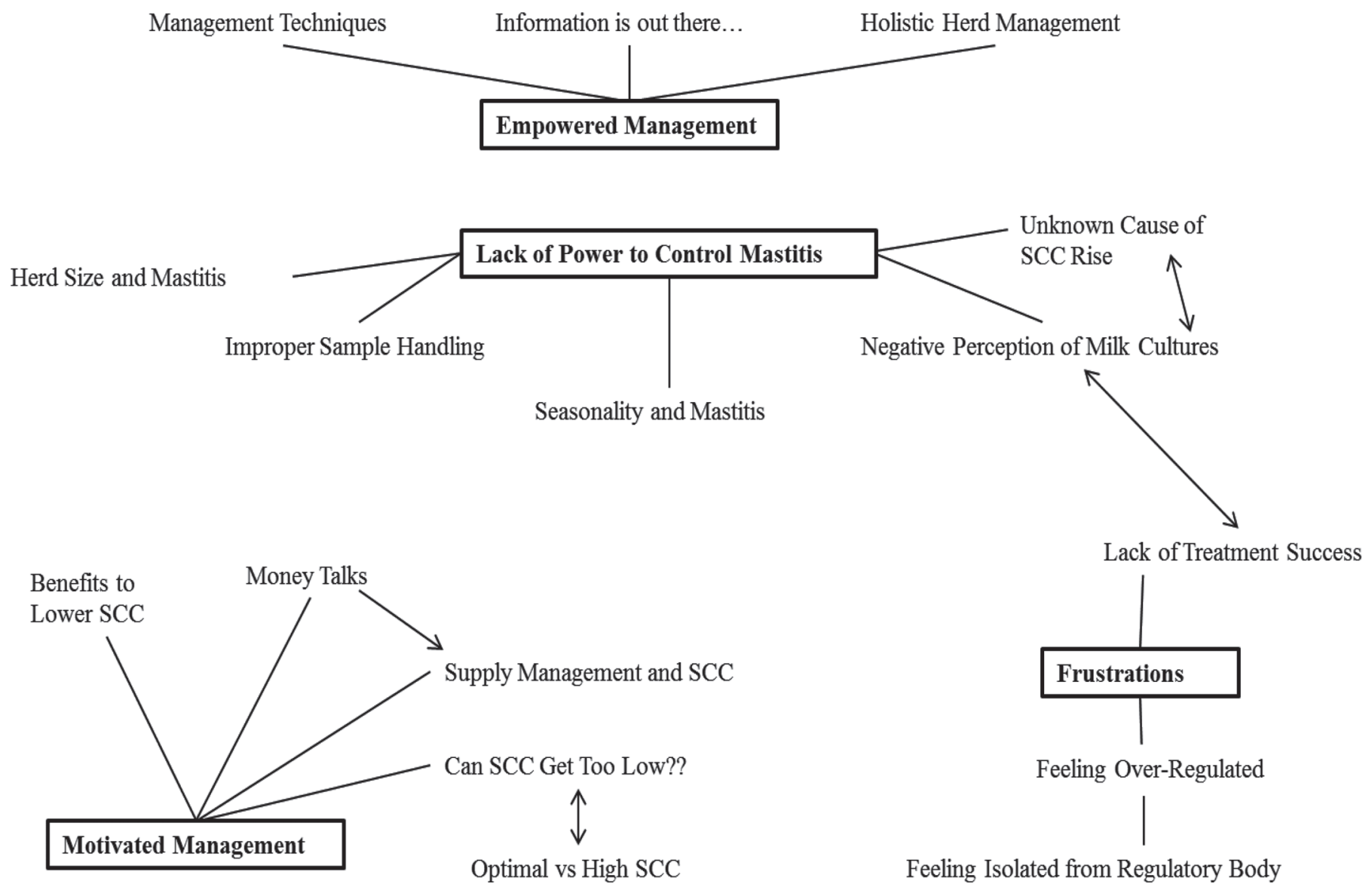

Figure 1. Thematic map outlining major themes and subthemes of thematic analysis generated from 5 focus groups conducted with Ontario dairy farmers in December 2011. 
information." Participants valued regular monitoring technologies and placed a high degree of important on these approaches to improve udder health.

Subtheme 2: "The Information Is Out There; You Gotta Go Get It." A common sub-theme across all focus groups was the notion that important information and support relating to the prevention and control of mastitis is readily available to producers. As suggested by one producer in the low SCC group, "I think there's lots of information out there and lots of opportunities, or places to go if you have a problem, right, got your dealers and the DFO staff and, your vet. There are certainly people there available to deal with an issue if there is an issue." Another producer from the medium SCC group echoed this sentiment, "I think it's [information on mastitis prevention] all out there, but you gotta go and get it, I guess." Producers indicated that they believe agricultural support professionals have a high level of understanding of the determinants of mastitis, and when producers take the initiative to seek it, this information is available and accessible to them.

Participants across all groups indicated they actively consult with several advisors on a regular basis to control mastitis on their farms. Overwhelmingly across the focus groups, the veterinarian was seen by the participating producers to be the most commonly accessed source of information on mastitis prevention practices. To a lesser extent, some producers also mentioned regular consultations with nutritionists, regulatory inspectors, and milking machine technicians. One producer from the low SCC group stated, "I think there's enough technology and support that you should be able to get things in check. You know, veterinarians and DHI." Taken further, one producer from the medium SCC group mentioned the importance of having a team approach to dealing with mastitis issues, "Nowadays it's more like a team approach ... you gotta work as a team. If your nutritionist, your vet, and your equipment dealer and, the way I look at it, everybody does their job in a team, everybody gets paid, everybody's happy." Use of the team approach for mastitis prevention and control was however not a commonly discussed topic. Overall, producers were happy with both the amount of information and the level of support available to them with regard to udder health with the common theme mentioned by several participants embodied by a statement by one participant: "The information is out there, you gotta go get it."

Subtheme 3: Holistic Herd Management. In only the southwestern Ontario low and medium SCC focus groups, participants discussed how a producer's general attitude toward the management of all aspects of the herd plays a significant role in controlling mas- titis risk. Specifically, these producers noted that, to have success in producing milk that is low in SCC, one must not only concentrate on the specific aspects of the farm that directly affect udder health, but one should also strive to excel in all aspects of management. They noted their perception of a strong association between producers that focused on quality management in all aspects of their herd and subsequent high-quality milk with low levels of BMSCC. One producer articulated this message well when he stated, "If you do everything right, quality is basically following your line. If you do things right, I don't think cell count will really be a big issue. Like if it is an issue, like if it flares up, then those kinds of people usually take action right away too. That's basically, like, if you do everything right, then you will do that right then too." Producers, specifically in the southwestern Ontario low SCC group, felt that preventative management in all facets of the enterprise, following best management practices, will naturally result in high quality milk that is low in SCC. Conversely, the southwestern Ontario low SCC group perceived those who routinely have problems with mastitis to be "messy" (cluttered and unhygienic) operators. As one low SCC producer stated, "Bad management ... Usually messy operators, right? You can see it when you come in the driveway, if everything is littered all over, well then you get to the barn and it's usually worse.... Yeah, that's what the, the salesmen usually say, they can tell when they hit the driveway what kind of a farm it is, right?"

\section{Theme 2: Lack of Power to Control Mastitis}

Although many producers participating in the focus group discussions identified strategies and situations that engendered empowered feelings toward managing mastitis, a variety of circumstances were identified where effective control over mastitis was perceived as unattainable. Five major subthemes were identified, including producer ignorance to the causes of BMSCC rise, issues with mastitis diagnostics, overwhelming summer mastitis challenges, limitations of having smaller herds, and improper sample handling on the part of regulatory authorities. Improper handling of samples was a minor subtheme and was not presented. Producers felt that these issues preclude control over the udder health situation on their farm. This theme was present across all groups of producers interviewed, with both high and low SCC producers feeling that, to varying degrees between groups, there are times when control over mastitis is not possible.

Subtheme 1: Unknown Cause of SCC Rise. Discussion involving the unknown cause of SCC rise and the management challenge this posed to control 
the rise was a topic that received considerable attention across the high SCC groups. The focus group that included producers in the low SCC category from eastern Ontario also touched upon this topic. During their discussions many of these participants noted having experienced situations where the root determinant (i.e., management practice, infection etiology) of their mastitis problem eluded them. These producers were frustrated when they received reports on their bulk tank and individual cows to indicate that they are infected; however, when they attempt to determine the cause through milk culture, they receive no diagnosis. One producer from the high SCC group noted, with respect to his bulk tank SCC, "Well and the thing is this, it does go up and down, and like, and why, I don't know...." Another producer indicated that, "Sometimes you wonder about these somatic cell counts from the, from DFO. One day it's at one sixty [thousand] and then two pickups later it's at five hundred [thousand] and then it drops, and you didn't change a thing!" During the focus group discussions, it was apparent, at times, producers had difficulty understanding why such variability existed in their BMSCC specifically.

Subtheme 2: Negative Perception of Milk Cultures. All focus groups had a general level of disappointment in milk culturing as a tool for managing mastitis. Specifically, producers seemed frustrated with the lag in the availability of culture results and with a low perceived level of sensitivity in detecting causal pathogens. One producer from the low SCC group stated, "But I mean if you want people to use it more, I think you better make it fast. If you have two days, I'm not going to wait two days. Now, we got to pay money to wait two days. To hell with that. They can pay me. I'm not going to wait two days. But I can't be that slow, it can't be that slow either." Another common thread leading to feelings of powerlessness in the face of mastitis was the high level of inconclusive culture results. An exchange between 2 producers in a high SCC group illustrated this well: producer 1 said, "Everything comes back negative, so I don't know what that's telling me," to which producer 2 replied, "Well, the worst part is when you send it, they culture it, come back, nothing found." Negative culture results also contribute to the previous subtheme of unknown causes of mastitis, whereby negative culture results leave farmers in the dark as to the cause for mastitis on their operation.

Subtheme 3: Seasonal Issues and Mastitis. Participating producers across all focus groups had similar feelings of powerlessness regarding the inevitable rise in mastitis cases that they experience during the summer months. The heat and humidity of the summer were seen as obstacles to preventing mastitis and maintain- ing low herd SCC. As one producer in the low SCC group noted, "when you get too, uh, hot, basically you're also going to start to get environmental problems. So basically, every cow will go up fairly quickly." Another producer from the same group supported this assertion when he stated, "I've seen, for several years, August is a change in weather coming, sometimes, and I don't know, August is a month that it might [provide] perfect growing conditions for bacteria." One producer, in the medium SCC group, also identified the fact that fieldwork compounds this elevation in SCC and mastitis rates, "The worst time is when you're busy in the field, you don't wanna have trouble in the barn."

Subtheme 4: Herd Size and SCC. The overall mean population herd size for the participating producers was 81 cows (Table 1 ); however for 3 of the 5 focus groups, the within-group average herd size was 60 cows. Several participants across focus groups recognized having difficulties maintaining low bulk tank SCC in a small herd setting. Producers with a small dairy herd $(<60$ cows $)$ felt size was a source of udder health issues that was not within their control. One producer from the medium SCC group noted, "When you have a small herd, one [cow with mastitis] can, boom! up in the penalty zone very fast. Instantly, yeah." Another producer from the high SCC group had similar feelings when he said, "Like if you have forty cows and have three bad ones it will spike you up as good as five in fifty or a hundred cows." Many producers outlined personal stories of instances where 1 or 2 cows have had a significant influence on their bulk tank SCC.

\section{DISCUSSION}

This study identifies motivations and attitudes that a subset of Ontario dairy producers hold toward udder health and mastitis control on their farms. Although the interviews were conducted in 2011, the results are still pertinent to the dairy industry. For instance, Ontario's provincial BMSCC varies year to year, but has on aggregate remained relatively unchanged since the time of the focus groups (CDIC, 2019). Further, the BMSCC penalty application algorithm has recently changed in Ontario (Government of Ontario, 2019), with penalties applied to producers who have over $40 \%$ of all milk shipments over a 3 -mo period above 400,000 cells $/ \mathrm{mL}$. These changes have left a substantial number of producers at risk of incurring penalties (personal communication, DFO), supporting the argument that mastitis remains a substantial challenge for the industry. Results indicate that, though some important attitudinal differences were present between producers in high versus low SCC groupings, several commonalities were also observed. 
The theory of planned behavior has been used for several decades as one of several models to predict human intention to perform an action (Ajzen, 2011). Recently, the theory has been used to explain the behaviors of dairy farmers in the context of hoof health (Bruijnis et al., 2013), animal welfare (Kauppinen et al., 2010), and mastitis treatment and prevention (Jansen et al., 2010b; Espetvedt et al., 2013). The theory itself proposes 3 independent determinants of intention, namely perceived behavioral control (the perceived level of difficulty to performing said behavior), a person's attitude toward a behavior in question (the degree to which a person has a favorable opinion of the behavior), and their subjective norm (the perceived social pressure to perform the behavior; Ajzen, 1991). This theory appears to align well with the findings of the current study in relation to the participants described behaviors and motivations relating toward udder health.

Two major themes identified in this paper deal with the producer's perceived control over the udder health status of their herd, namely "empowered management" and conversely, the "lack of control over udder health." As part of the theory of planned behavior, the control that a producer perceives to have over udder health is influenced by the actual behavioral control - the time, knowledge, and resources available to the producer to combat mastitis, along with self-efficacy beliefs - the producer's strength of belief in their ability to control the udder health situation on their farm (Ajzen, 1991). Participating producers across the focus groups felt as though they possessed the tools, information resources, and ability necessary to combat udder health issues on their farms. The most commonly discussed management practices identified were culling chronically infected cows and monitoring bulk tank and individual cow SCC. In many cases, dairy producers do have a high degree of actual behavioral control over culling decisions in their herd, with culling chronically infected cows being a highly efficacious and economically efficient method of rapidly lowering herd SCC (Kuiper et al., 2005). Overall, culling of high SCC cows was the most commonly and extensively discussed management practice to control SCC. This is a disappointing finding, given the fact that culling high SCC cows is more of a short-term solution that does not sustainably address udder health issues like other management practices (e.g., bedding management, udder preparation). This theme is also in keeping with previous research that found that most producers are highly confident in their ability to control herd SCC (Jansen et al., 2010b; Kuiper et al., 2005).

Under the subtheme "holistic management," producers described the whole dairy farm as an entity over which they could exert control, focusing on broad "best management practices" in areas such as nutrition, reproduction, cow comfort, and environmental hygiene. Through proactive management and control of all these general areas, optimal udder health would naturally follow. Producers contrasted this idea with the image of "messy operators" as being the herds that do not focus their attention on best management practices across the operation, and are more likely to experience poor udder health. This argument aligns with Barkema et al. (1999), who noted that producers that spent the time to manage each part of the dairy in a methodological and accurate manner were more likely to have success in udder health.

In contrast to this high level of self-efficacy in the control of herd SCC, many producers also identified areas where they perceived a low level of control over udder health on their farm. The theory of cognitive dissonance states that individuals experiencing internal psychological conflicts attempt to restore balance by eliminating this conflict (Cameron, 2009). Control beliefs are based on past experiences, the presence of requisite resources, second-hand experience, and perceived barriers, where the higher the perceived barriers to controlling mastitis, the lower the level of perceived behavioral control of the situation (Ajzen, 1991). One potential example of dissonance reduction from the present study is demonstrated in the belief of some participants that there were adverse health risks associated with low SCC levels, therefore justifying or rationalizing the need for higher SCC levels. Although some reports have noted that herds maintaining low SCC levels had higher rates of clinical mastitis, specifically due to gram-negative pathogens (Erskine et al., 1988; Green et al., 1996; Barkema et al., 1998), other studies have failed to find an association (Hoblet et al., 1988; Peeler et al., 2003; Zecconi et al., 2004). Most of the evidence supports the notion that a lower SCC is a healthier state of being for both the cow and the herd. As a result, dairy extension professionals can assist producers by delivering a clear message that, while excessively low BMSCC may be detrimental (e.g., BMSCC $<100,000$ cells $/ \mathrm{mL}$ ), low SCC levels should still be the goal, as the risk for clinical mastitis is significantly greater for cows with high SCC levels. Though producers across the focus groups expressed relatively high levels of confidence in their ability to deal with udder health issues, there were still some clear examples in which perceived control over the situation was low, contributing to producer conflict, especially among participants in the high SCC focus groups.

Another important subtheme that limited producer self-efficacy in mastitis control centered on the unknown etiologic causes for mastitis and SCC elevations. Participants described experiencing fluctuations 
in udder health status over time, and often they did not understand the cause. Prior research indicates that mastitis management can be ad hoc and up to $30 \%$ of producers feel a significant gap in their own knowledge with respect to preventing mastitis (Kuiper et al., 2005). Experiencing unexplained periods of mastitis could also indicate that participants might not be fully utilizing the available services for education or to evaluate the udder health issues on their farm. In the case of fluctuating bulk tank SCC, the detection intensity of clinical and subclinical mastitis could be sub-optimal for these producers, leading to the inclusion of mastitic and high SCC milk in the bulk tank.

Unknown etiologic causes for mastitis and SCC elevations were also linked to the frustrations participants expressed surrounding inconclusive milk culture results. Studies have found that 20 to $50 \%$ of mastitic milk samples submitted to the diagnostic laboratory yield no bacterial growth (Makovec and Ruegg, 2003). Following the theory of planned behavior, producers that have a negative attitude toward a particular behavior, in this case culturing the milk from clinically infected cows, could be less likely to perform this behavior. Consultants need to work with producers to help them understand the limitations and importance of bacteriological culturing of clinical and subclinical cases to foster both a positive attitude toward culturing, and the confidence that the results of the cultures may further empower the producer to minimize mastitis on their farm. Further, on-farm consultants could focus on other diagnostic approaches (e.g., PCR, epidemiologic analysis) to better understand farm-specific pathogen pressure.

The theory of planned behavior provides a useful model to interpret and contextualize the attitudes and motivations of participating Ontario dairy producers in this study. Participants expressed diverse opinions concerning their perceived behavioral control over the udder health on their farm. Notably, culling and monitoring BMSCC, along with a focus on applying best management practices in all facets of their enterprises, engendered the perception that mastitis could be controlled. Conversely, participating producers perceived certain situations where mastitis was difficult to control (for example, low herd sizes, improper sample handling, heat and humidity of the summer), which led to low levels of perceived behavioral control. Farm advisors need to first recognize the potential for negative attitudes toward beneficial behaviors, and second devise ways to minimize and prevent such attitudes from occurring. This effort starts with a clear and detailed explanation of the procedures, their benefits, drawbacks, and the concerns or risks that could be experienced should they go unimplemented. Further, producers face a variety of social expectations and pressures (regulatory bodies, consultants, society) that, in turn, shape their response to BMSCC issues (i.e., participants would react when they perceive that regulators expect them to maintain BMSCC below the regulatory threshold). Under periods of increased demand for milk (production incentive days), participating producers shifted their management, potentially at the expense of the udder health situation on their farm. Though they generally had a negative attitude toward this behavior, they likely faced a shift in subjective norms, whereby the expectation that they meet these production incentives could be perceived as being more important than optimizing udder health, especially considering the latitude afforded to them during these times before financial penalties for high BMSCC levels are applied. Regulators need to be cognizant of the potential to engender negative attitudes toward the behavior they wish to promote, potentially risking unwilling compliance of producers.

The results of this study should be interpreted in the light of the recruited producers not being a wholly representative sample of population and in the context that Canada is among the last countries in the world with a functioning dairy supply management system. Further, the authors have a high degree of knowledge in mastitis control measures, and this likely shaped the themes generated from the analysis. Despite this, every effort was given to ensure the themes generated were well supported by the data. The results are nonetheless telling in terms of producer behavior and motivation to improve udder health.

\section{CONCLUSIONS}

The participating dairy farmers from Ontario shared several attitudes and beliefs about mastitis prevention and udder health in common with their international counterparts (Kuiper et al., 2005; Jansen et al., 2009, 2010c). Though farmers generally have high levels of self-efficacy beliefs when it comes to udder health management, the perception still exists that, under certain situations, mastitis is uncontrollable. This highlights the fact that educational and extension efforts need to focus on ensuring that producers employ proven mastitis diagnostic, prevention, and treatment practices in a systematic manner, with realistic expectations.

\section{ACKNOWLEDGMENTS}

The authors thank Mai Pham (University of Guelph, Guelph, ON, Canada) for her work to facilitate all focus groups. As well, thanks to all producers who participated in this research. This research was funded by the 
Dairy Farmers of Ontario (Mississauga, ON, Canada). The authors have not stated any conflicts of interest.

\section{REFERENCES}

Ajzen, I. 1991. The theory of planned behavior. Organ. Behav. Hum. Decis. Process. 50:179-211. https://doi.org/10.1016/0749 -5978(91)90020-T.

Ajzen, I. 2011. The theory of planned behaviour: Reactions and reflections. Psychol. Health 26:1113-1127. https://doi.org/10.1080/ 08870446.2011.613995.

Barkema, H. W., Y. Schukken, T. Lam, M. Beiboer, H. Wilmink, G. Benedictus, and A. Brand. 1998. Incidence of clinical mastitis in dairy herds grouped in three categories by bulk milk somatic cell counts. J. Dairy Sci. 81:411-419. https://doi.org/10.3168/jds .S0022-0302(98)75591-2.

Barkema, H. W., J. D. Van der Ploeg, Y. H. Schukken, T. J. G. M. Lam, G. Benedictus, and A. Brand. 1999. Management style and its association with bulk milk somatic cell count and incidence rates of clinical mastitis. J. Dairy Sci. 82:1655-1663. https://doi .org/10.3168/jds.S0022-0302(99)75394-4.

Braun, V., and V. Clarke. 2006. Using thematic analysis in psychology. Qual. Res. Psychol. 3:77-101. https://doi.org/10.1191/ 1478088706qp063oa.

Bruijnis, M., H. Hogeveen, C. Garforth, and E. Stassen. 2013. Dairy farmers' attitudes and intentions towards improving dairy cow foot health. Livest. Sci. 155:103-113. https://doi.org/10.1016/j.livsci .2013.04.005.

Cameron, K. A. 2009. A practitioner's guide to persuasion: An overview of 15 selected persuasion theories, models and frameworks. Patient Educ. Couns. 74:309-317. https://doi.org/10.1016/j.pec .2008.12.003

CDIC. 2019. Milk Quality Monthly Cell Counts [Internet]. Government of Canada. Accessed Jul. 24, 2019. https://www.dairyinfo.gc .ca/index_e.php?s1=dff-fcil\&s2=farm-ferme\&s3=ssbc-clbt.

Creswell, J. W. 2013. Qualitative Inquiry and Research Design: Choosing Among Five Approaches. 3rd ed. SAGE, Thousand Oaks, CA.

Erskine, R. J., S. B. Spencer, M. A. Campbell, R. J. Eberhart, and L. J. Hutchinson. 1988. Incidence and types of clinical mastitis in dairy herds with high and low somatic cell counts. J. Am. Vet. Med. Assoc. 192:761-765.

Espetvedt, M., A. Lind, C. Wolff, S. Rintakoski, A. Virtala, and A. Lindberg. 2013. Nordic dairy farmers' threshold for contacting a veterinarian and consequences for disease recording: Mild clinical mastitis as an example. Prev. Vet. Med. 108:114-124. https://doi .org/10.1016/j.prevetmed.2012.07.014.

Government of Ontario. 2019. R.R.O. 1990, Reg. 761: Milk and Milk Products [Internet]. Ontario Milk Act. Accessed Jul. 24, 2019. https://www.ontario.ca/laws/regulation/900761.

Green, M., L. Green, and P. Cripps. 1996. Low bulk milk somatic cell counts and endotoxin-associated (toxic) mastitis. Vet. Rec. 138:305-306. https://doi.org/10.1136/vr.138.13.305.

Hoblet, K., J. Bailey, and D. Pritchard. 1988. Coagulase-positive Staphylococcal mastitis in a herd with low somatic-cell counts. J. Am. Vet. Med. Assoc. 192:777-780.

Hogeveen, H., K. Huijps, and T. J. G. M. Lam. 2011. Economic aspects of mastitis: New developments. N. Z. Vet. J. 59:16-23. https: //doi.org/10.1080/00480169.2011.547165.

Jansen, J., B. H. P. van den Borne, R. J. Renes, G. van Schaik, T. J. G. M. Lam, and C. Leeuwis. 2009. Explaining mastitis incidence in Dutch dairy farming: The influence of farmers' attitudes and behaviour. Prev. Vet. Med. 92:210-223. https://doi.org/10.1016/j .prevetmed.2009.08.015.

Jansen, J., R. J. Renes, and T. J. G. M. Lam. 2010a. Evaluation of two communication strategies to improve udder health management. J. Dairy Sci. 93:604-612. https://doi.org/10.3168/jds.2009-2531.

Jansen, J., G. van Schaik, R. J. Renes, and T. J. G. M. Lam. 2010b. The effect of a national mastitis control program on the attitudes, knowledge, and behavior of farmers in the Netherlands. J. Dairy Sci. 93:5737-5747. https://doi.org/10.3168/jds.2010-3318.

Jansen, J., C. D. M. Steuten, R. J. Renes, N. Aarts, and T. J. G. M. Lam. 2010c. Debunking the myth of the hard-to-reach farmer: Effective communication on udder health. J. Dairy Sci. 93:12961306. https://doi.org/10.3168/jds.2009-2794.

Kauppinen, T., A. Vainio, A. Valros, H. Rita, and K. M. Vesala. 2010. Improving animal welfare: Qualitative and quantitative methodology in the study of farmers' attitudes. Anim. Welf. 19:523-536.

Kolstrup, C. L., M. Kallioniemi, P. Lundqvist, H. Kymalainen, L. Stallones, and S. Brumby. 2013. International perspectives on psychosocial working conditions, mental health, and stress of dairy farm operators. J. Agromedicine 18:244-255. https://doi.org/10.1080/ 1059924X.2013.796903.

Krueger, R. A., and M. A. Casey. 2009. Focus Groups: A Practical Guide for Applied Research. 4th ed. Sage Publications Inc., Thousand Oaks, CA.

Kuiper, D., J. Jansen, R. Renes, C. Leeuwis, and H. van der Zwaag. 2005. Social Factors Related to Mastitis Control Practices: The Role of Dairy Farmers' Knowledge, Attitude, Values, Behaviour and Networks. Wageningen Academic Publishers, Wageningen, the Netherlands.

Lam, T. J. G. M., J. Jansen, B. H. P. van den Borne, R. J. Renes, and H. Hogeveen. 2011. What veterinarians need to know about communication to optimise their role as advisors on udder health in dairy herds. N. Z. Vet. J. 59:8-15. https://doi.org/10.1080/ 00480169.2011.547163.

Makovec, J. A., and P. L. Ruegg. 2003. Results of milk samples submitted for microbiological examination in Wisconsin from 1994 to 2001. J. Dairy Sci. 86:3466-3472. https://doi.org/10.3168/jds .S0022-0302(03)73951-4.

Peeler, E. J., M. Green, J. Fitzpatrick, and L. Green. 2003. The association between quarter somatic-cell counts and clinical mastitis in three British dairy herds. Prev. Vet. Med. 59:169-180. https:// doi.org/10.1016/S0167-5877(03)00076-X.

Sargeant, J. M., Y. H. Schukken, and K. E. Leslie. 1998. Ontario bulk milk somatic cell count reduction program: Progress and outlook. J. Dairy Sci. 81:1545-1554. https://doi.org/10.3168/jds.S0022 -0302(98)75720-0.

Steeneveld, W., A. G. J. Velthuis, and H. Hogeveen. 2014. Short communication: Effectiveness of tools provided by a dairy company on udder health in Dutch dairy farms. J. Dairy Sci. 97:1529-1534. https://doi.org/10.3168/jds.2013-7132.

Tong, A., P. Sainsbury, and J. Craig. 2007. Consolidated criteria for reporting qualitative research (COREQ): A 32-item checklist for interviews and focus groups. Int. J. Qual. Health Care 19:349-357. https://doi.org/10.1093/intqhc/mzm042.

Vaarst, M., B. Paarup-Laursen, H. Houe, C. Fossing, and H. J. Andersen. 2002. Farmers' choice of medical treatment of mastitis in Danish dairy herds based on qualitative research interviews. J. Dairy Sci. 85:992-1001. https://doi.org/10.3168/jds.S0022 -0302(02)74159-3.

Zecconi, A., R. Piccinini, and L. Fox. 2004. Epidemiological study of non-contagious intramammary infections in nine commercial dairy herds following a Staphylococcus aureus control programme. J. Vet. Med. B Infect. Dis. Vet. Public Health 51:333-336. https://doi .org/10.1111/j.1439-0450.2004.00787.x.

\section{ORCIDS}

D. A. Shock ๑ https://orcid.org/0000-0003-0796-6820

S. J. LeBlanc @ https://orcid.org/0000-0003-2027-7704

K. E. Leslie @ https://orcid.org/0000-0001-9804-2628

D. Renaud () https://orcid.org/0000-0002-3439-3987

S. Roche @ https://orcid.org/0000-0001-6934-6497

K. Hand $\odot$ https://orcid.org/0000-0002-8969-3418

M. A. Godkin (1) https://orcid.org/0000-0002-7154-5791

D. F. Kelton () https://orcid.org/0000-0001-9606-7602 
APPENDIX

\section{APPENDIX A: FOCUS GROUP INTERVIEW GUIDE TO ELICIT ATTITUDES, PERCEPTIONS, AND MOTIVATIONS SURROUNDING UDDER HEALTH}

\section{Attitudes Toward Mastitis/High SCC}

1. Take a moment to think about the biggest issues or concerns on dairy farms in Ontario right now... where does mastitis/high bulk tank SCC currently rank among these issues?

2. Why do you think some producers have lower SCC than others (or cows/herds with less mastitis)?

a. Why do you think some producers have higher SCC than others (or cows/herds with more mastitis)?

b. What do you think are some advantages to having a lower SCC?

3. At what level would you be concerned about your bulk tank SCC?

a. At what SCC level would feel you needed to take action to reduce your bulk tank SCC?

b. Is there anything that frustrates you about bulk tank SCC?

4. (If applicable) Has anyone here received a letter from the Ontario Dairy Industry Working Group about their SCC penalty risk? Or heard about another dairy producer receiving this letter?

a. Was anyone surprised by the assessment of their SCC penalty risk?

b. What effect do you think the lowering in the regulatory standard for SCC in raw milk will have on Ontario dairy producers?

\section{Attitudes to Seeking Help for Mastitis/High SCC}

5. What would be some of the things you would do if you felt mastitis or SCCs were a problem on your own farm?

a. Who or where would you go for help?

b. Is there anything that makes it difficult for you to deal with SCCs or mastitis issues on your own farm?

6. On your farm, do you have a vet actively working with you on mastitis on an ongoing basis? How?

a. How about your other advisors - what kind of help do you get from them regarding SCCs and mastitis?

7. What do you think about mastitis treatment? (is it useful, successful, has this changed?, etc.) a. How are you doing now with mastitis compared with 10 years ago? Has anything changed for you that you think affects mastitis in your herd in that time interval?

b. What are some of your past successes with mastitis or SCCs?

8. Where do you usually get information that you use to make decisions about SCCs and mastitis on your farm?

a. For your own situation are there some topics or issues about mastitis and SCCs that you personally would like to get more information on?

b. Do you think producers need more information on mastitis and SCCs?

c. Are there any particular tools or kinds of information that you use to help address mastitis issues (i.e., DHI, CowSCCs)?

\section{APPENDIX B: THEMES NOT DISCUSSED IN THE CURRENT PUBLICATION}

\section{Motivated Management}

Every focus group was able to identify the benefits and in turn motivations to attaining and maintaining a lower herd SCC. Producers briefly mentioned motivations such as increased milk production, healthier herds, longer shelf life of fluid milk, an enhanced media perception of the dairy industry, and improved food safety. As one producer in the low SCC group put it, "you want a low cell count anyways. Your herd is healthier and you produce more milk like if you look at the information that's out there, like... It's like two, three hundred liters per lactation." Another producer in the low SCC group noted an improvement in product quality in lower SCC milk stated, "you get better shelf life out of a product that has a lower somatic cell count." Another producer from the medium SCC group stated, in reference to why he strived to lower his SCC, "people sometimes forget, we're not only producers, we're consumers ourselves too... That's the way we try to look at it on our farm ... if I don't wanna drink that milk ...it's not gonna be shipped."

The overwhelming majority of producers cited financial motivations as their major driver of maintaining lower SCC.

\section{Money Talks}

Producers in all focus groups mentioned the risk of incurring financial penalties as a strong motivator 
Table A1. Consolidated criteria for reporting qualitative studies (Tong et al., 2007)

\begin{tabular}{l} 
Item \\
\hline Domain 1: Research team and \\
reflexivity \\
Personal characteristics \\
Interviewer/facilitator \\
Credentials \\
Occupation \\
Sex \\
Experience and training \\
Relationship with participants \\
Relationship established \\
Participant knowledge of the \\
interviewer \\
Interviewer characteristics \\
Domain 2: Study design \\
Theoretical framework \\
Methodological orientation \\
and theory \\
Participant selection \\
Sampling \\
Method of approach
\end{tabular}

Sample size

Nonparticipation

Setting

Setting of data collection

Presence of nonparticipants

Description of sample

Data collection

Interview guide

Repeat interviews

Audio/visual recording

Field notes

Duration

Data saturation

Transcripts returned

Domain 3: Analysis and findings

Data analysis

Number of data coders

Description of coding tree

Derivation of themes

Description

Answer

Which author(s) conducted the focus groups?

What were the author's credentials?

What was their occupation at the time of the study?

Was the researcher male or female?

What experience or training did the researcher have?

Was a relationship established before study commencement?

What did the participants know about the researcher?

What characteristics were reported about the facilitator?

What methodological orientation was stated to underpin the study?

How were participants selected?

How were participants approached?

How many participants were in the study?

How many people refused to participate or dropped out? Reasons?

Where was the data collected?

Was anyone else present besides the participants and researchers?

What are the important characteristics of the sample?

Were questions, prompts, guides provided by the authors? Was it pilot tested?

Were repeat interviews carried out? If so, how many?

Did the research use audio/video recording to collect the data? Were field notes made during or after the focus groups (or both)?

How long were the focus groups?

Was data saturation discussed?

Were transcripts returned to participants for comment, correction, or both?

How many coders coded the data?

Did authors provide a description of the coding tree?

Were themes identified in advance, or derived from the data?
Author D. Shock was an assistant. Focus groups were conducted by a trained facilitator.

MS in epidemiology

Doctoral graduate student

Female

Facilitator development certificate, extensive experience conducting focus group interviews

No

Participants had no knowledge of the facilitator before the interviews.

It was divulged that both the facilitator and assistant were graduate students at the University of Guelph.

Thematic analysis

Based on herd udder health parameters during the summer of 2011 (see methods)

A list of producers that met study criteria was generated and they were contacted by phone by an employee of the milk marketing board.

34 producers participated in the study.

160 producers contacted by phone declined to participate. Lack of time and interest was the major reason provided. 6 producers failed to attend the focus group. 3 phoned with regrets, and 3 did not attend for unknown reasons.

Focus groups were conducted in a rented restaurant room (3 in Tavistock, ON, Canada) and a community center (Maxville, ON, Canada) No

A questionnaire was completed by all participants outlining herd characteristics, bulk tank SCC, acres worked, age of participants, sex, number of employees, and the availability of Internet.

Yes to both questions

No repeat interviews were conducted.

All focus groups were audio recorded.

Yes, field notes were maintained.

Between 79 and 106 min

No

No. The facilitator did check back with participants at the end of all focus groups to ensure that she understood everything that was discussed.

One person coded with ongoing discussion between all authorship.

The coding process was described in the manuscript.

An inductive (bottom-up) approach was employed, where themes were derived from the data.

Continued 
Table A1 (Continued). Consolidated criteria for reporting qualitative studies (Tong et al., 2007)

\begin{tabular}{lll}
\hline Item & Description & Answer \\
\hline Software & $\begin{array}{l}\text { What software, if applicable, was used to } \\
\text { manage the data? }\end{array}$ & ATLAS.ti (Berlin, Germany) \\
Participant checking & $\begin{array}{l}\text { Did participants provide feedback on the } \\
\text { findings? }\end{array}$ & $\begin{array}{l}\text { Participant provided feedback at the end of all focus } \\
\text { group interviews, but did not provide feedback on the } \\
\text { findings. }\end{array}$ \\
$\begin{array}{ll}\text { Reporting } \\
\text { Quotations presented }\end{array}$ & $\begin{array}{l}\text { Were participant quotations presented to } \\
\text { illustrate the themes/findings? Was each }\end{array}$ & Yes \\
quotation identified? & \\
Wata and findings consistent & $\begin{array}{l}\text { Was there consistency between the data } \\
\text { presented and the findings? }\end{array}$ & Yes \\
Clarity of major themes & $\begin{array}{l}\text { Were major themes clearly presented in } \\
\text { the findings? } \\
\text { Is there a description of diverse cases or } \\
\text { discussion of minor themes? }\end{array}$ & Yes \\
\hline
\end{tabular}

to improve the udder health situation on their farm. "Penalties, penalties make you react... so the penalty has to stay in place, because if it's not gonna hurt you financially, and it will hurt you, lost production, but you don't really feel that. But if you've gotta pay then it's 'Oh, I better change."' Participants' conversations focused on producers that maintain herd SCC at levels that are close to the penalty threshold, their only motivation being to avoid adverse financial repercussions. The general mentality was one that, outside of financial penalty for maintaining higher SCC, a large proportion of producers have no incentive to lower their herd SCC. One producer from the low SCC group stated, "But of all the people, they just run at the penalty level just below that, and that's where they'll stay. If you lower it, those'll go a little lower and operate underneath." Another producer from the same group supported this point when he said, "It's maybe unpleasant for the guy that always is down there, and for whatever reason he slides into it. And get the heck back out. But that guy will try everything to go back in line." A producer from the high SCC focus group echoed this sentiment when he stated, "Well, if they're gonna stay in business, they're gonna have to deal with it." Producers perceived high levels of unpleasantness and risk associated with penalties for elevated BMSCC, and this feeling was enough of a motivator to lower herd SCC.

Another area of discussion that received considerable attention across all focus groups centered on the motivation that would arise if the milk marketing board adopted the practice of offering financial premiums for producing lower SCC milk. When discussing the potential motivation that a financial premium would offer, one producer in the low SCC group of southwestern Ontario stated, "I know, I would put more effort into it. Money talks right? Might go down, actually." One organic producer in the low SCC group spoke about the role of direct financial incentives in driving fellow organic producers to strive for lower BMSCC and mastitis prevention when he said, "We [Canadian organic producers] get a premium for low bacteria and low somatic cell. And I know that DFO, a lot of you guys are saying 'Why shouldn't we be getting the same thing?', right? It helps, because I can show you on the chart from organic farmers how we're all trying for that premium." A further sentiment expressed by several producers was that the premiums might actually be more effective in motivating producers to control their SCC. One producer from the high SCC group stated, "Well its [a financial premium for lower SCC] better than, it's better than penalizing it." Put in a different light, one producer in the low SCC group noted, "I think enticing is better than the stick for motivating people."

\section{Supply Management and SCC}

An area that was discussed across all focus groups was the interaction between supply management and udder health. Producers across groups noted that in the fall, when there is an incentive to produce more milk, they would do so at the expense of udder health. A statement by one in the low SCC group producer embodied this sentiment when he stated, in reference to the added production incentives offered to producers in autumn, "now, when there's lots of milk to be shipped, I'll live with that problem [high SCC] cow," illustrating the drive participants spoke of being induced by the immediate financial benefits of producing more milk regardless of the cost to herd udder health. Another producer from the same group echoed this opinion when he said, "In the fall especially with the incentive program that they put in place, the focus is on more milk getting out the door. The more you get paid. So there's really 
no big incentive other than the five hundred thousand penalty for producing high-quality milk. You know, you hang on, I'm as guilty of it as anybody else, you hang on to any old bag that produces milk, yeah."

Generally, producers indicated that elevated BMSCC levels were problematic with respect to lost milk and risk of financial penalty; however, when faced with the financial ramifications of not filling their quota demands, they routinely choose to continue milking high SCC cows. One producer from the high SCC group noted, "If you're low on quota, and I do it myself too, if I'm low on quota and I know my somatic cell's around three hundred and it shouldn't be, well I'm not gonna kick that cow out, you know." Another participant in the same group reiterated this point by stating, "I think there's the time, if you're short of milk trying to fill your quota, you're more liable to let it go. If you're over quota, well then you can treat the animal, take it out or beef it or something."

\section{Optimal Versus High SCC}

When producers were asked about their perceptions of what constitutes an optimal or high BMSCC, a vast diversity of opinions was expressed. As a general trend, low SCC focus groups had specific, low levels of BMSCC that they strove to achieve. One producer in the low SCC group stated, "The best thing is, for somatic cell count, the numbers between one hundred, and one fifty. I think that's the best rate you can have." Another producer from the medium SCC group indicated, "I like to see it [bulk tank SCC] under two hundred...." In contrast, producers in the high SCC groups considered optimal and high herd SCC as one and the same. For participants in the high SCC groups, the optimal BMSCC level was anything lower than the penalty threshold. Their discussions focused on a perception of what constituted a high BMSCC, namely the penalty threshold. When asked about the level of bulk tank SCC that would cause a producer to take action, one producer in the high SCC group indicated, "Well, it's always at the penalty level so I mean, if it's gonna be four hundred then anything over three hundred, start sounding the alarms." For this producer, the bulk tank penalty level is a strong motivator to control mastitis, and their level of concern that will determine preventative action is set close to this penalty threshold. This producer further elaborated, "So if it [the bulk tank SCC regulatory threshold] gets lowered to two hundred and fifty, then I'll be concerned at two hundred thousand." Another producer from the high SCC group cited the 300,000 cells/mL SCC level as a motivator to corrective action when he stated "Over three hundred... better start taking some cows out of line or something. Start to think about it." One low SCC producer agreed with this when he said, "What range would you get worried? Well, if you get three hundred thousand you really, I think I would start looking." Within the focus group discussions producers in the low SCC group framed their conversations around proactively striving for a lower herd SCC before problems arise, whereas producers in the medium and high SCC groups consistently spoke of mainly reacting to BMSCC levels that they perceived as high, rather than striving for lower BMSCC levels. The level perceived by most producers across the focus groups as "high," and thus necessitating corrective action, was typically cited as 300,000 cells $/ \mathrm{mL}$.

\section{Can SCC Get Too Low?}

One theme that received considerable attention by participants in 3 focus groups (the 2 low and 1 medium SCC groups) was the question of whether low SCC could be detrimental to the health of both the individual cow and the herd in general. For the producers in the focus groups in which this topic was discussed, many felt that it is possible for the SCC of a cow or herd to get too low, and that low SCC levels are indicative of an inadequate immune response, further predisposing to mastitis infections. One producer in the low SCC group stated, "I like my somatic cell count to be high enough so that they build antibodies so that if they get an infection they can fight it off." Despite this sentiment, there was much disagreement as to whether or not excessively low SCC can have detrimental health effects. When one producer in the low SCC group from southwestern Ontario claimed, "Actually if you come beneath one hundred [less than 100,000 cells/mL], then it's too low actually, the cow gets an infection, then it's, uh, most like the cow's gone... the immune system, was not built up," another producer replied, "Well, that's not the case... we tested all the cows individually... and we were actually pretty alarmed when we had one cow with seven hundred thousand in one quarter, but I have seen a lot of cows quarterly that only like, uh, a thousand cell count. A lot of them. And, and that's, and basically that's the same thing, doesn't matter where you are, even here, the lower your cell count is, the less problems you have." Another producer in the medium SCC group of southwestern Ontario stated, "I think the cow that has the lowest somatic cell count is the one that gets sick, because it's got no resistance." Again, this statement was met with a contradictory opinion when another participant postulated, "I don't know, I have a hunch-I used to think that way, I have a hunch the lower it is, they might take longer to get mastitis. Then again, I don't know, I just have a hunch." 


\section{Frustrations}

Participants across all focus groups discussed a broad range of issues that engendered feelings of frustration associated with mastitis control. In particular, producers felt there was a lack of support from their marketing board (DFO), in large part due to the increasing regulatory framework being imposed upon their enterprises by the DFO. Also, when dealing with udder health issues, there was significant disappointment with the results associated with treating clinical mastitis cases. In addition, producers harbored frustrations associated with results obtained from culturing cows with suspected IMI.

\section{Feeling Overregulated}

In large part, and throughout all focus groups, producers expressed feelings of resentment stemming from the perception that milk quality regulations have been excessively tightened. When speaking of the regulatory BMSCC threshold change from 500,000 to 400,000 cells $/ \mathrm{mL}$, one producer from the low SCC group stated, "Or, lowering our, the penalty level. Where is too much, too much?... I just find we're already pushing the boundaries - I understand the advantage of it, but aren't we already at a significantly higher level [of quality based on lower SCC threshold] than what the Americans...?" This producer elaborated on further new on-farm regulations that required increased record keeping and development of standard operating procedures when he said, "It's a bit overkill I think... A lot of the stuff we're doing already... I guess it's all, to meet, uh, export regulations, but we're not exporting anyways so where's our - why are we spending all this money on aggravation? To, to comply with an export market when we're not exporting."

\section{Feeling Isolated from Regulatory Body}

In addition to feeling resentment, participants perception of over-regulation of the quality of milk fostered feelings of isolation among participants from the DFO in Ontario. Producers perceived that, historically, they received adequate levels of support from this regulatory body; however, during more recent times, they felt as though they could not turn to this same organization for support of their udder health problems. Much of these feelings seemed to coincide with the DFO's changing mandate of regulation, coupled with the termination of udder health consulting services. One producer in the low SCC group stated, "Talking to some of the neighbors, they feel that the dairy producer is at the bottom of the ladder within our own organization. If you run into trouble, the last person you want to call is your fieldman, where twenty-five years ago or when I started farming it was the first guy you called... if you run into trouble, you have no backup or no support from our own organization." A participant from another (high SCC) focus group felt that, "He [the field service representative for the DFO] should be the source for us, no matter what, to contact and say 'Hey, what do you think about this? I think it's off.' He should be right there and say, 'Well this program says this, the new study says that. I would do this and this to try.' But he will come out and say, 'It's not my problem. You don't comply, I penalize.' ... We're almost, we're almost scared to contact them... because he will look at this, and he will see that, he will just open a bag of worms." Another producer from the same focus group agreed when he said, "Back before the milk board took over the milk inspection... our field reps were really like another consultant in our business. And you know, we dealt with them on quota issues...now we don't dare...you would like to have it so that, you know, if we did have a problem with the farm that you'd say, 'Can you come over here, just give me your perspective on things?"'

\section{Lack of Treatment Success}

Though several adjunct mastitis treatment strategies were noted (i.e., topical udder creams, oxytocin, organic options), the majority of producers indicated they treat clinical mastitis with intramammary antibiotics. Some producers noted moderate levels of success in treating mastitis with intramammary antibiotics, but the majority of participants expressed frustration with a perceived high level of treatment failure, and a resulting increase in chronically infected animals in their herd, "I don't know, I always focus on prevention [of mastitis] because I've never had much success with treatment." Another producer related his perceived treatment failures when he said, "What works this year don't work next year. It gets immune to it or something." Another producer estimated his level of treatment success when using intramammary antibiotics when he stated, "I'd say fifty percent, like it works sometimes, sometimes it doesn't, and there's no one brand that seems to control everything." 